\title{
Role of Transobturator Tape in the Treatment of Mixed Urinary Incontinence in Women
}

\author{
Neelakandan R. ${ }^{1}$, Jagadish Kaushik B. ${ }^{2}$, Chandru T. ${ }^{3}$, Natarajan K. ${ }^{4}$ \\ ${ }^{1}$ Department of Urology, Sri Ramachandra Medical College and Hospital, Porur, Tamilnadu, India. ${ }^{2}$ Department of \\ Urology, Sri Ramachandra Medical College and Hospital, Porur, Tamilnadu, India. ${ }^{3}$ Department of Urology, Sri \\ Ramachandra Medical College and Hospital, Porur, Tamilnadu, India. ${ }^{4}$ Department of Urology, Sri Ramachandra \\ Medical College and Hospital, Porur, Tamilnadu, India.
}

\section{ABSTRACT}

\section{BACKGROUND}

Globally, urinary incontinence (UI) is frequently observed in women and impairs every aspect of her life. Mixed urinary incontinence (MUI) refers to the presence of both stress (SUI) and urgency urinary incontinence (UUI). There are variable cure rates of midurethral slings (MUS) procedures in MUI. Thus, the present study was performed to evaluate the effectiveness of transobturator tape (TOT) technique, influence of outside-in TOT on objective and subjective cure rates and quality of life, and to assess the post-operative complications in women with MUI.

\section{METHODS}

This was a prospective interventional study involving 31 women who had undergone TOT procedure for MUI at Department of Urology, Sri Ramachandra Medical Centre \& Sri Ramachandra Medical College Hospital, Chennai, over the last 2 years. The study was performed over a period of 25 months (i.e., September 2016 to September 2018). MUI was diagnosed on the basis of urodynamic tests such as pressure flow study. Urodynamic evaluation was done using Laborie urodynamic device. All patients filled in the International Consultation on Incontinence Questionnaire-Short Form (ICIQ-SF) both pre-operatively and post-operatively (at 6 months). Incontinence bothersome scale (IBS) was used to evaluate post-operative satisfaction and if the IBS score was $>80$, patient was considered to be satisfied. All patients were routinely evaluated at 2 weeks post-operatively and then on the $6^{\text {th }}$ month post-operatively with pelvic examination, cough stress test (CST), IBS score, and ICIQ-SF.

\section{RESULTS}

Majority of patients belonged to the age group of 41-50 years (35.4\%) and were post-menopausal (61.3\%). Post-operatively, there was a significant decrease in the number of patients with symptoms related to both SUI and UUI $(<0.05)$. Moreover, there was significant postoperative increase in Pdet $Q \max (<0.05)$ and a reduction of maximum flow (Qmax) $(<0.05)$. Subjective and objective SUI cure was achieved in $90.32 \%$ and $87.09 \%$ patients, respectively. While, subjective UUI cure was achieved in $70.96 \%$ patients. VAS score $>80$ was observed in $77.41 \%$ patients. Only 5 patients developed post-operative complications including dyspareunia, severe groin pain, recurrent UTI, and urinary retention.

\section{CONCLUSIONS}

During follow-up, TOT procedure was found to be highly successful in the treatment of MUI. There was no incidence of injury to urethra or bladder, and no complications related with bowel or nervous system. Hence, TOT will definitely improve MUI control, decrease women's dissatisfaction, and improve quality of life.

\section{KEYWORDS}

Midurethral Slings, Mixed Urinary Incontinence, Transobturator Tape, Urinary Incontinence
Corresponding Author: Dr. Neelakandan R., Department of Urology, E2-OPD, Medical Centre, Ramachandra Medical College \& Hospital, Porur-600116, Tamilnadu, India.

E-mail:drneelakandan@gmail.com

DOI: 10.14260/jemds/2019/770

Financial or Other Competing Interests: None.

How to Cite This Article:

Neelakandan R, Kaushik JB, Chandru T, et al. Role of transobturator tape in the treatment of mixed urinary incontinence in women. J. Evolution Med. Dent. Sci. 2019;8(48):3563-3568, DOI: 10.14260/jemds/2019/770

Submission 19-06-2019, Peer Review 10-11-2019, Acceptance 19-11-2019, Published 02-12-2019. 


\section{BACKGROUND}

International Continence Society (ICS) defines urinary incontinence (UI) as an involuntary passage of urine. ${ }^{1}$ Whereas, mixed urinary incontinence (MUI) is the simultaneous presence of both stress urinary incontinence (SUI) and urgency urinary incontinence (UUI) and is linked to both effort, exertion, sneezing, or coughing as well as urgency. ${ }^{2}$

UI is highly prevalent in women and adversely affects every aspect of woman's life i.e., physical, psychological, and social resulting in low self-esteem, embarrassment, and decreased productivity at work place. ${ }^{3,4}$ However, as compared to women suffering from SUI, women with MUI are at least two-fold more likely to be worried by the symptoms. ${ }^{5}$ Primarily, SUI is most prevalent, but during late adulthood, MUI is an extremely predominant subtype. ${ }^{6}$

Predominant symptom, that is most troublesome to the patients, generally determines the treatment. ${ }^{7}$ Non-surgical treatment is considered as the first-line treatment and includes weight loss, behaviour modification, pelvic floor muscle training, reduced fluid intake, caffeine moderation, biofeedback, anti-incontinence devices, and pharmacological treatment.2,7,8 While, surgical treatment is an option for women with stress-predominant MUI or with equal components of SUI and UUI, and not responding to nonsurgical interventions. These includes urethral bulking agents, retropubic suspensions, bladder neck slings, or midurethral slings. ${ }^{2,8}$ Among these surgical methods, midurethral sling (MUS) procedures such as transobturator tape (TOT) and tension-free vaginal tape (TVT) are most widely used. ${ }^{2}$ Some studies have reported that TOT is more promising to result in total resolution of MUI, due to its less obstructive nature.9,10 However, no significant difference in outcomes is validated by a recent meta-analysis. ${ }^{11}$

Available data reports variable cure rates of MUI after MUS surgery. ${ }^{11-14}$ Moreover, such data from the perspective of adult Indian women is lacking. Thus, the present study was performed with an objective of evaluating the effectiveness of TOT in the treatment of women with MUI. Secondary objectives of the present study were to determine the influence of outside-in TOT on objective and subjective cure rates and quality of life, and to assess the postoperative complications in women with MUI.

\section{METHODS}

This was a prospective Interventional study involving 31 women, attending Department of Urology, Sri Ramachandra Medical Centre \& Sri Ramachandra Medical College Hospital, Chennai. The study was performed over a period of 25 months (i.e., September 2016 to September 2018). The study commenced only after the approval of Institutional Ethics Committee.

Women aged 21 years or more; diagnosed both clinically and urodynamically as a case of MUI; had failed 3 months of conservative treatment; and having positive pad test \& cough stress test were included in the study. While, women with presence of pelvic organ prolapse ( $>$ stage 1); known history of neurological disorder; urodynamically proven impaired bladder contractility; previous urethral reconstruction; morbid obesity $\left(\mathrm{BMI}>40 \mathrm{Kg} / \mathrm{m}^{2}\right)$; and pregnancy were excluded. A total of 31 women who underwent transobturator taping procedure for MUI in our institution over the last 2 years were requested to participate in this study. On acceptance, written informed consent was obtained. All the women were evaluated through a thorough history, pelvic examination with focused neurological examination, ultrasound scan of the abdomen with post-void residual (PVR), pad and cough stress test, urodynamic evaluation \& cystoscopy. MRI of the pelvis \& spine was reserved for women with abnormal focused neurological examination.

Patient characteristics included in the study were age, body mass index (BMI), menopausal status, parity with mode of delivery, previous pelvic surgical history, the number of pads used per day, symptom duration, pre- and postoperative urodynamic study (UDS) parameters, intraoperative parameters, post-operative complications and surgical outcomes.

Urodynamic tests such as pressure flow study were performed in all patients for the diagnosis of MUI. Urodynamic evaluation was done using Laborie urodynamic device. A sterile $8 \mathrm{~F}$ dual channel cystometry catheter was placed into the urethra and a rectal catheter with $10 \mathrm{ml}$ balloon was placed into the rectum. The urinary bladder was filled with saline solution at the rate of $40 \mathrm{ml} / \mathrm{min}$ and the patient was asked to cough after each $100 \mathrm{ml}$ filling. Urinary incontinence occurring in this time was detected, detrusor instability during the filling phase was also noted. Abdominal leak-point pressure was measured in all patients and recorded. On confirming a diagnosis of MUI, a free-flow without catheter was performed. All patients filled in the International Consultation on Incontinence QuestionnaireShort form (ICIQ-SF) pre-operatively and post-operatively at 6 months. All patients, after obtaining anaesthetist clearance, underwent outside-in TOT procedure as described by Leval. ${ }^{15}$ All surgeries were done under regional/general anaesthesia. Post-procedure cystoscopy was done to assess urethra and bladder. All patients were monitored with the Foley catheter for bladder drainage for 48-72 hours.

Incontinence bothersome scale (IBS) was used to evaluate post-operative satisfaction. Where, 0 represented very dissatisfied/intolerable urinary complaints and 100 represented very satisfied/no urinary problems. If the IBS score was $>80$, patient was considered to be satisfied. All patients were routinely evaluated at 2 weeks postoperatively and then on the $6^{\text {th }}$ month post-operatively with pelvic examination, cough stress test (CST), IBS score, and ICIQ -SF.

- Objective cure: negative CST with no need for pads or any form of surgical intervention.

- $\quad$ Subjective cure: 0 point on ICIQ-SF and an IBS score of > 80.
Statistical Analysis
Categorical data was expressed as absolute numbers and percentages and the continuous data was expressed as mean \pm standard deviation (SD). Statistical analyses were performed with SPSS 17.0 (SPSS version 17.0, Chicago, IL, USA). A p-value of $\leq 0.05$ was considered as statistically significant. 


\section{RESULTS}

Table 1 depicts the demographic profile and risk factors of the study population. Majority of patients i.e., 11 each, belonged to the age group of 41-50 years and had BMI in the range of $25-29.9 \mathrm{Kg} / \mathrm{m}^{2}$. The mean age and the mean BMI of the patients were $51.90 \pm 10.46$ years and $27.2 \pm 4.35 \mathrm{Kg} / \mathrm{m}^{2}$, respectively. Majority of the women i.e., 19 were postmenopausal. Majority of women i.e., 25 had a past history of vaginal delivery and the mean parity was $2.38 \pm 1.12$. Majority of the patients i.e., 19 used $\leq 4$ pads per day and the mean pads used per day was $4.03 \pm 1.79$. Among patients with past history of pelvic surgeries, majority i.e., 5 had caesarean section. Majority of the patients i.e., 17 had symptoms for 1-5 years and the mean symptoms duration was $4.45 \pm 1.95$ years.

\begin{tabular}{|c|c|c|}
\hline Parameters & Number of Patients & Percentage of Patients \\
\hline \multicolumn{3}{|c|}{ Age Group (in Years) } \\
\hline $31-40$ & 5 & 16.2 \\
\hline $41-50$ & 11 & 35.4 \\
\hline $51-60$ & 6 & 19.4 \\
\hline $61-70$ & 9 & 29.0 \\
\hline \multicolumn{3}{|c|}{ BMI (in $\mathrm{Kg} / \mathrm{m}^{2}$ ) } \\
\hline $15-19.9$ & 2 & 6.4 \\
\hline $20-24.9$ & 8 & 25.8 \\
\hline $25-29.9$ & 11 & 35.5 \\
\hline $30-34.9$ & 8 & 25.8 \\
\hline $35-39.9$ & 2 & 6.4 \\
\hline \multicolumn{3}{|c|}{ Menopausal Status } \\
\hline Pre-menopausal & 12 & 38.7 \\
\hline Post-menopausal & 19 & 61.3 \\
\hline \multicolumn{3}{|c|}{ Parity } \\
\hline 0 & 1 & 3.2 \\
\hline 1 & 4 & 12.9 \\
\hline 2 & 13 & 41.9 \\
\hline$>2$ & 13 & 41.9 \\
\hline \multicolumn{3}{|c|}{ Mode of Delivery } \\
\hline Vaginal & 25 & 80.6 \\
\hline LSCS & 5 & 16.2 \\
\hline Nulliparous & 1 & 3.2 \\
\hline \multicolumn{3}{|c|}{ Prior Pelvic Surgeries } \\
\hline None & 23 & 74.2 \\
\hline Caesarean section & 5 & 16.2 \\
\hline Vaginal hysterectomy & 2 & 6.4 \\
\hline $\begin{array}{c}\text { Abdominal } \\
\text { hysterectomy }\end{array}$ & 1 & 3.2 \\
\hline \multicolumn{3}{|c|}{ Symptoms Duration (in Years) } \\
\hline$<1$ & 2 & 6.4 \\
\hline $1-5$ & 17 & 54.9 \\
\hline$>5$ & 12 & 38.7 \\
\hline \multicolumn{3}{|c|}{ Number of Pads Used } \\
\hline $1-4$ pads & 19 & 61.3 \\
\hline$>4$ pads & 12 & 38.7 \\
\hline
\end{tabular}

\begin{tabular}{|c|c|c|c|}
\hline UDE Parameters & Pre-Operative & Post-Operative & $\mathbf{p}$ \\
\hline Cystometric capacity (ml) & $396.90 \pm 46.98$ & $371.96 \pm 43.50$ & $<0.05$ \\
\hline Detrusor over-activity & $26(83.87 \%)$ & $23(74.19 \%)$ & $\mathrm{xx}$ \\
\hline PdetQmax $\left(\mathrm{cmH}_{2} \mathrm{O}\right)$ & $16.35 \pm 1.99$ & $25.22 \pm 4.32$ & $<0.05$ \\
\hline $\mathrm{Qmax}(\mathrm{ml} / \mathrm{s})$ & $25.54 \pm 5.50$ & $18.45 \pm 5.22$ & $<0.05$ \\
\hline Urodynamic SUI & $31(100 \%)$ & $4(12.90 \%)$ & $<0.05$ \\
\hline Abdominal Leak Point Pressure & $98.48 \pm 7.75$ & - & - \\
\hline \multicolumn{4}{|c|}{ Table 2. Pre- and Post-Operative Urodynamic Parameters } \\
\hline \multicolumn{4}{|c|}{$\begin{array}{l}\text { Data expressed as mean } \pm \text { SD, absolute numbers, and percentage; } p \text {-value } \leq 0.05 \\
\text { was considered as statistically significant. Please write the specific statistical test } \\
\text { used. }\end{array}$} \\
\hline
\end{tabular}

\begin{tabular}{|c|c|c|}
\hline \multicolumn{3}{|c|}{ Pre-Operative ICIQ-SF Score } \\
\hline Score & N = 31 & Percentage (\%) \\
\hline$>15$ & 17 & 54.8 \\
\hline \multicolumn{3}{|c|}{ Intra-operative Parameters } \\
\hline Parameters & Mean \pm SD & Range \\
\hline Operative time (in minutes) & $29.83 \pm 5.08$ & $20-40$ \\
\hline Hospital stay (in days) & $1.61 \pm 0.61$ & $1-3$ \\
\hline Table 3. Pre-Operative ICIQ-SF Score and Intra-Operative Parameters \\
\hline $\begin{array}{l}\text { ICIQ-SF - International Consultation on Incontinence Questionnaire-Short form. } \\
\text { Please write post-operative ICIQ-SF score as well \& whether there was any } \\
\text { statistically significant change. }\end{array}$ \\
\hline
\end{tabular}

\begin{tabular}{|c|c|}
\hline Post-Operative Complications & n (\%) \\
\hline \multicolumn{2}{|c|}{$\begin{array}{l}\text { Grade I } \\
\end{array}$} \\
\hline Dyspareunia & $2(40)$ \\
\hline \multicolumn{2}{|c|}{ Grade II } \\
\hline Severe groin pain & $1(20)$ \\
\hline Recurrent UTI & $1(20)$ \\
\hline \multicolumn{2}{|c|}{ Grade III a } \\
\hline Urinary retention & $1(20)$ \\
\hline \multicolumn{2}{|c|}{ Total } \\
\hline Total & $5(100)$ \\
\hline
\end{tabular}

\begin{tabular}{|c|c|}
\hline Outcome Measures & n (\%) \\
\hline Subjective SUI cure & $28(90.32)$ \\
\hline Objective SUI cure & $27(87.09)$ \\
\hline Subjective UUI cure & $22(70.96)$ \\
\hline Patient satisfaction (IBS> 80) & $24(77.41)$ \\
\hline Total & $31(100)$ \\
\hline
\end{tabular}

SUI- stress urinary incontinence; UUI - urgency urinary incontinence; IBSIncontinence bothersome scale.

Table 2 depicts pre- and post-operative urodynamic parameters. Post-operatively, there was a significant decrease in the number of patients with symptoms related to both SUI and UUI $(<0.05)$. Moreover, there was significant postoperative increase in PdetQmax $(<0.05)$ and a reduction of maximum flow (Qmax) $(<0.05)$.None of the patients had a significant PVR either pre- or post-operatively.

Table 3 depicts pre-operative ICIQ-SF score and intraoperative parameters. Majority of the patients i.e., 17 had a score of $\leq 15$ and the mean ICIQ-SF score was $15.03 \pm 1.88$ Post-operative ICIQ-SF score was less than 3 in all patients post TOT repair.

Table 4 depicts post-operative complications according to modified Clavien classification system. In the immediate postoperative period, 1 patient developed severe groin pain requiring prolonged analgesics. One patient developed urinary retention, requiring Foley's catheterisation, and was very-well able to pass urine 1 week after catheter removal. One patient had recurrent UTI, on urine culture E. Coli was identified and was treated with oral Levofloxacin $500 \mathrm{mg}$ OD for 2 weeks. Since her symptoms persisted, she was further prescribed oral Nitrofurantoin $200 \mathrm{mg}$ BD for 2 weeks. During follow-up after 6 months, 2 patients complained of persisting dyspareunia, which was managed conservatively with local application of oestrogen.

Table 5 depicts surgical outcomes among patients at the post-operative $6^{\text {th }}$ month. Subjective cure from SUI and UUI was seen in 28 and 22 patients, respectively. Patients with persisting UUI were prescribed Solifenacin $5 \mathrm{mg}$ OD and performed better. Objective cure from SUI was noticed in 27 patients, and 1 patient had negligible leak which was detected on UDS, but not perceived by the patient. The overall patient satisfaction assessed through the IBS score of $>80$ was noted in 24 patients.

\section{DISCUSSION}

Global epidemiological studies have reported increasing prevalence of UI with increase in age, but each subtypes of UI has a different order of prevalence as per the age group involved. As per available evidence, prevalence of SUI (mean $=13 \%)$ is most during the $5^{\text {th }}$ decade of life, and then decreases. While, prevalence of UUI (mean $=5 \%$ ) and MUI (mean $=11 \%)$ is low during young age $(20-30$ years $)$, but 
steadily increases with age. ${ }^{6}$ MUI may result from two separate pathologies involving combination of bladder dysfunction and a leaky urethral sphincter, or principally involving a leaky urethral sphincter, leading to passage of urine into the proximal urethra, thereby resulting in both reflexive detrusor contractions and urgency incontinence, as well as stress incontinence, in between. ${ }^{7}$ Extensive literature search failed to retrieve any data regarding epidemiology and risk factors related exclusively to MUI in Indian women. Various epidemiological studies in India have reported variable prevalence of MUI. Agarwal et al., ${ }^{16}$ Bhanu et al., ${ }^{17}$ and Singh et al., ${ }^{18}$ reported the prevalence of MUI as 38\%,34.6\%, and $16.8 \%$, respectively. This may be due to different settings and study population.

The muscle fiber to connective tissue ratio and muscle fiber diameter in the urethral sphincter decreases with increase in age. Thus, similar age-related changes may develop in the pelvic floor, resulting in deficient support in old women and ultimately UI. ${ }^{3}$ In the present study, majority of the patients $(35.4 \%)$ belonged to the age group of $41-50$ years and had a mean age of $51.90 \pm 10.46$ years. Similarly, Abdel-Fattah et al. Reported the mean age of $55.14 \pm 10.97$ years in women with MUI. ${ }^{13}$ Biswas et al. Reported the mean age of $61.91 \pm 9.69$ years and maximum prevalence in $\geq 70$ years-old women.19 Thus, mean age and age group of our study participants correlate well with the studies cited in literature. In the present study, majority of the patients $(61.3 \%)$ had achieved menopause. However, contrary to our finding, Singh et al. Reported that $22.5 \%$ of the patients were post-menopausal. ${ }^{18}$ Kirss et al. in their study reported high prevalence of UI in post-menopausal women, where only $21.17 \%$ of post-menopausal women had MUI.210 Thus, increasing age and postmenopausal status are important risk factors of UI. In the univariate analysis, we found no significant risk factor for persistence of SUI. Mean age of $>60$ years and menopause were significant predictive factors for persistence of UUI ( $p=0.008$ and $p=0.04$, respectively). Mean age $>60$ years $(p=0.009)$ was predictive of persistence of overall incontinence.

Increased BMI is linked to greater prevalence of SUI, due the reason that increased abdominal pressure on the bladder area, results in the greater risk of SUI. Moreover, chronically elevated abdominal pressure may lead to stressed pelvic floor. ${ }^{3}$ In the present study, majority of the patients (35.4\%) had a BMI in the range of $25-29.9 \mathrm{Kg} / \mathrm{m}^{2}$ and a mean BMI of $27.2 \pm 4.35 \mathrm{Kg} / \mathrm{m}^{2}$. Similarly, Abdel-Fattah et al. Reported the BMI of $\geq 30 \mathrm{~kg} / \mathrm{m}^{2}$ in $44.0 \%$ women with MUI. ${ }^{13}$ Contrary to the present study, Biswas et al. Reported that the majority of patients (70.1\%) had a normal BMI (18.5-24.9 Kg/m²). Studies have demonstrated inverse relationship between parity and strength of pelvic floor muscles. Thus, as the number of deliveries increase, the strength of pelvic floor muscles decreases. ${ }^{3}$ In the present study, majority of the patients (83.8\%) had a parity of $\geq 2$. Similarly, Biswas et al. reported that the majority of patients $(54.2 \%)$ had a parity of $\geq 4$. Singh et al. reported that multiparity is associated with UI and $17.6 \%$ multiparous women had MUI.

Incidence of UI is more with vaginal deliveries than caesarean, due to increased chances of weakness of pelvic floor muscles. Caesarean delivery usually protects the functions of pelvic nerve and muscle. ${ }^{3}$ In the present study, majority of the patients $(80.6 \%)$ had vaginal delivery, thus supporting the findings in the literature. Similarly, Singh et al. reported that maximum prevalence of UI was among patients with vaginal delivery (26.84\%), which was significantly higher than nulliparous women $(9.42 \%)$ and women with caesarean deliveries (8.59\%).18 These findings demonstrate that the mechanical strain during the labor may further increase the risk related to the pregnancy itself. Moreover, history of gynaecological surgery such as LSCS and hysterectomy increases the chances of trauma to the urinary tract, thereby increasing the risk of UI. Majority of the women $(74.2 \%)$ in the present study, had no past history of pelvic surgeries, while majority of women with past history of pelvic surgery had LSCS $(16.2 \%)$. Similar to the present study, Biswas et al. Reported that only $10.7 \%$ patients had a past history of gynaecological surgery and $4.5 \%$ had past history of LSCS. ${ }^{19}$

The mean duration of symptoms were $4.45 \pm 1.95$ years. There was a significance delay in asking for medical help. From the data collected, it appears that most women tend to seek treatment between 1-5 years after the onset of symptoms. Reasons for this delay could be ranging from personal to economical to logistical. ${ }^{21}$ In patients with MUI, urodynamic studies (UDS) are generally recommended before invasive procedures and surgery and they predict treatment outcome. ${ }^{7}$ In terms of treatment success and patient satisfaction, pre-operative UDS has not been found superior to office evaluation of UUI before surgery. ${ }^{22}$ In the present study, UDS failed to identify SUI in 3 patients, but we have done TOT based on positive cough stress test and SUI history. Also, we could not confirm detrusor over-activity (DO) in 7 patients who had incontinence with strong urge. When there is a disagreement between the UDS and the patient's symptoms, UDS findings are not superior to the patient's symptoms. Inability to report DO or SUI on UDS does not exclude the importance of patient's symptoms. ${ }^{23}$

In the present study, on UDS, 28 women had demonstrable SUI pre-operatively, whereas only 4 women had SUI post-operatively, where it was negligible in one patient $(4 \mathrm{ml})$ and she did not notice the leak. UUI disappeared in 23 patients (74.2\%); urgency, which was present pre-operatively in all 31 patients, persisted in 9 patients $(29 \%)(\mathrm{p}<0.05)$. Frequency, which was present preoperatively in 26 patients, persisted in 6 patients $(19.3 \%)$ $(p<0.05)$. There were no patients with worsening of overactive bladder (OAB) symptoms. All patients with postoperative storage symptoms were treated with Solifenacin 5 $\mathrm{mg}$ and had a good clinical response.

The urodynamic data revealed a statistically significant postoperative increase in $P \operatorname{det} Q \max (p=0.02)$ and $a$ reduction of maximum flow (Qmax) ( $p=0.03)$. No obstruction, according to the Blaivas and Groutz nomogram, was observed in any patient post-operatively. ${ }^{24}$ The mean procedural time was $29.83 \pm 5.08$ minutes, including an additional cystoscopy at the end of the procedure. This was similar to mean operative time of TVT reported by Abouassaly et al. ${ }^{25}$

The present study demonstrates that patients with MUI, who have not responded to conservative treatment, can achieve a significant improvement of both the stress and the urge components following a TOT procedure. The surgical management of women with MUI is a subject of debate among clinicians. Some authors have published positive 
results, even though, cure rates following MUS were significantly lower in patients with MUI than in patients with pure SUI.11,26,27 Cure rates of SUI do not differ from that in patients with pure SUI, but $30-70 \%$ still suffer from urgency symptoms. ${ }^{27,28}$ Cure rates are even lower in patients with urge predominant MUI.27,28

In a meta-analysis, Jain et al. evaluated retropubic TVT and TOT in patients with MUI, and reported no significant difference in overall subjective cure of SUI and urinary urgency, frequency and UUI. ${ }^{11}$ However, a RCT comparing TVT and TOT in MUI patients in terms of all storage symptoms revealed cure rates of 31\% after TVT and 55\% after TOT. ${ }^{29}$ In a prospective RCT comparing TVT and TOT in patients with SUI or MUI, Nyyssonen et al. reported that a large proportion of patients with MUI found the operation beneficial for urge symptoms. In a median follow-up of 46 months, the subjective and objective cure rates in TOT group were $81 \%$ and $74 \%$, respectively. Urge symptoms were relieved in $70 \%$ of patients in MUI subgroup. ${ }^{30}$ In an another study, Gamble et al. assessed the efficacy of transobturator, retropubic or bladder neck sling in 305 women with MUI and concluded that transobturator slings had the lowest rate of persistent DO. 31

Abdel-Fattah et al. in a RCT compared outside-in and outside-in TOT in 66 patients with MUI and reported a subjective success rate of $73.8 \%$, with a clinically significant improvement in quality of life (QoL) of $86.7 \%$. The cure rates of urgency and urgency incontinence were $50.1 \%$ and $56.5 \%$, respectively and there were no significant differences between the two groups. ${ }^{14}$ Results of the present study are consistent with the findings in the literature, as the cure rates of urgency and UUI were lower than that of SUI. Significant relationship between DO and failure of TOT surgery finds its mention in some studies. Jain et al. in their meta-analysis observed that studies which excluded patients with DO reported higher cure rates for UUI. ${ }^{11}$ Similarly, Paick et al. found that coexisting DO increases the risk of both persistent urgency and UUI. ${ }^{32}$ Findings of the present study concur with these studies.

In the present study, overall complication rate of $16.92 \%$ was comparable to other studies with the complication rates ranging from $10.5 \%$ to $31.3 \% .33,34$ It has been advocated that de novo urgency rate is lower in TOT compared to other midurethral sling procedures. ${ }^{34}$ None of the patients experienced worsening of UUI. Various studies have demonstrated that the transobturator tape is very much away from the pudendal nerve, obturator vessels and nerve, and the femoral vessels. The risk of lower urinary tract injury or other visceral injury is negligible with this approach when compared to TVT. ${ }^{35,36}$ In a study involving 107 SUI patients, de Leval demonstrated no injuries related to bladder or urethra and absence of vascular or neurologic complications. ${ }^{15}$

In the present study, none of the patients had signs and symptoms of vaginal, urethral, or bladder injury or erosions; or persistent pain during the 6 months follow-up period. Prolonged postoperative groin pain was seen in 1 patient in this study. The cause for the postoperative pain with this procedure was probably due to a less predictable, more lateral passage of the needle and thus, a closer exit to the obturator nerve in the groin. Oral analgesics were sufficient and she was pain-free during the follow-up at 3 months.
The strengths of the present study are the prospective design; the inclusion of women with only MUI with predominant SUI; UDS were performed both pre- and postoperatively; and pre- and post-operative assessment of symptoms with validated questionnaires. The limitations of the study were short duration of the follow-up and absence of a control group.

\section{CONCLUSIONS}

TOT procedure was found to be highly successful in the treatment of MUI during follow-up. The outside-in transobturator technique is simple, quick, and safe. It allows the accurate passage of the tape with minimal dissection. Both menopause and age over 60 are risk factors for failure of surgery. Surgeons should take this into account when counselling the patient on the likelihood of persistence of UUI and SUI symptoms. Finally, TOT will definitely improve MUI control, increase women's satisfaction, and improve their quality of life. However, long-term comparative studies are needed to assess the efficacy of TOT in patients with MUI.

\section{REFERENCES}

[1] Haylen BT, de Ridder D, Freeman RM, et al. An International Urogynecological Association (IUGA)/International Continence Society (ICS) joint report on the terminology for female pelvic floor dysfunction. Int Urogynecol J 2010;21(1):5-26.

[2] Kammerer-Doak D, Rizk DEE, Sorinola 0, et al. Mixed urinary incontinence: International Urogynecological Association Research and Development Committee Opinion. Int Urogynecol J 2014;25(10):1303-12.

[3] Sharma T, Mittal P. Risk factors for stress urinary incontinence in women. International Journal of Contemporary Medical Research 2017;4(10):2031-5.

[4] Abdel-Fattah M, Cao G, Mostafa A. Long-term outcomes for transobturator tension-free vaginal tapes in women with urodynamic mixed urinary incontinence. Neurourol Urodyn 2017;36(4):902-8.

[5] Minassian VA, Devore E, Hagan K, et al. Severity of urinary incontinence and effect on quality of life in women by incontinence type. Obstet Gynecol 2013;121(5):1083-90.

[6] Minassian VA, Bazi T, Stewart WF. Clinical eidemiological insights into urinary incontinence. Int Urogynecol J 2017;28(5):687-96.

[7] Chughtai B, Laor L, Dunphy C, et al. Diagnosis, evaluation, and treatment of mixed urinary incontinence in women. Rev Urol 2015;17(2):78-83.

[8] Welk B, Baverstock RJ. The management of mixed urinary incontinence in women. Can Urol Assoc J 2017;11(6 Suppl 2):S121-S4.

[9] Gomelsky A, Dmochowski RR. Treatment of mixed urinary incontinence in women. Curr Opin Obstet \& Gynecol 2011;23(5):371-5.

[10] Brucker BM. Expectations of stress urinary incontinence surgery in patients with mixed urinary incontinence. Rev Urol 2015;17(1):14-9. 
[11] Jain P, Jirschele $\mathrm{K}$, Botros SM, et al. Effectiveness of midurethral slings in mixed urinary incontinence: a systematic review and meta-analysis. Int Urogynecol J 2011;22(8):923-32.

[12] Heinonen P, Ala-Nissila S, Raty R, et al. Objective cure rates and patient satisfaction after the transobturator tape procedure during 6.5-year follow-up. Journal of Minimally Invasive Gynecology 2013;20(1):73-8.

[13] Abdel-Fattah M, Mostafa A, Young D, et al. Evaluation of transobturator tension-free vaginal tapes in the management of women with mixed urinary incontinence: one-year outcomes. Am J Obstet Gynecol 2011;205(2):150.e1-6.

[14] Abdel-Fattah M, Hopper LR, Mostafa A. Evaluation of transobturator tension-free vaginal tapes in the surgical management of mixed urinary incontinence: 3-year outcomes of a randomized controlled trial. The Journal of Urology 2014;191(1):114-9.

[15] De Leval J. Novel surgical technique for the treatment of female stress urinary incontinence: transobturator vaginal tape inside-out. Eur Urol 2003;44(6):724-30.

[16] Agarwal BK, Agarwal N. Urinary incontinence: prevalence, risk factors, impact on quality of life and treatment seeking behaviour among middle aged women. Int Surg J 2017;4(6):1953-8.

[17] Bhanu P, Nilanchali S, Shalini R. Prevalence and risk factors of urinary incontinence during antenatal period in women delivering in a tertiary care centre of Northern India. Int $\mathrm{J}$ of Community Med Public Health 2017;4(6):2071-4.

[18] Singh U, Agarwal P, Verma ML, et al. Prevalence and risk factors of urinary incontinence in Indian women: a hospital-based survey. Indian J Urol 2013;29(1):31-6.

[19] Biswas B, Bhattacharyya A, Dasgupta A, et al. Urinary incontinence, its risk factors and quality of life: a study among women aged 50 years and above in a rural health facility of West Bengal. J Mid-life Health 2017;8(3):1306.

[20] Kirss F, Lang K, Toompere K, et al. Prevalence and risk factors of urinary incontinence among Estonian postmenopausal women. Springerplus 2013;2:524.

[21] Tubaro A. Risk Factors for Urinary Incontinence in Women. Current Opinion in Urology 2001;11(1):110-1.

[22] Nager CW, Brubaker L, Litman HJ, et al. A randomized trial of urodynamic testing before stress incontinence surgery. N Engl J Med 2012;366(21):1987-97.

[23] Scarpero H. Urodynamics in the evaluation of female LUTS: When are they helpful and how do we use them? Urol Clin North Am 2014;41(3):429-38, viii-ix.

[24] Blaivas JG, Groutz A. Bladder outlet obstruction nomogram for women with lower urinary tract symptomatology. Neurourol Urodyn 2000;19(5):553-64.
[25] Abouassaly R, Steinberg JR, Lemieux $M$, et al. Complications of tension-free vaginal tape surgery: a multi-institutional review. BJU Int 2004;94(1):110-3.

[26] Sinha D, Blackwell A, Moran PA. Outcome measures after TVT for mixed urinary incontinence. Int Urogynecol J Pelvic Floor Dysfunct 2008;19(7):927-31.

[27] Kulseng-Hanssen S, Husby H, Schiotz HA. Follow-up of TVT operations in 1,113 women with mixed urinary incontinence at 7 and 38 months. Int Urogynecol J Pelvic Floor Dysfunct 2008;19(3):391-6.

[28] Athanasiou S, Grigoriadis T, Giannoulis G, et al. Midurethral slings for women with urodynamic mixed incontinence: what to expect? Int Urogynecol J 2013;24(3):393-9.

[29] Kocjancic E, Costantini E, Frea B, et al. Tension free vaginal tape vs. transobturator tape: Is there any difference in the mixed incontinence patients? Results of multicentre randomized trial. Eur Uro Suppl 2008;7(3):123.

[30] Nyyssonen V, Talvensaari-Mattila A, Santala M. A prospective randomized trial comparing tension-free vaginal tape versus transobturator tape in patients with stress or mixed urinary incontinence: subjective cure rate and satisfaction in median follow-up of 46 months. Scand J Urol 2014;48(3):309-15.

[31] Gamble TL, Botros SM, Beaumont JL, et al. Predictors of persistent detrusor overactivity after transvaginal sling procedures. Am J Obstet Gynecol 2008;199(6):696.e1-7.

[32] Paick JS, Oh SJ, Kim SW, et al. Tension-free vaginal tape, suprapubic arc sling and transobturator tape in the treatment of mixed urinary incontinence in women. Int Urogynecol J Pelvic Floor Dysfunct 2008;19(1):123-9.

[33] Yonguc T, Gunlusoy B, Degirmenci T, et al. Are the outcomes of transobturator tape procedure for female stress incontinence durable in long-term follow-up? Int Urol Nephrol 2014;46(7):1295-300.

[34] Novara G, Artibani W, Barber MD, et al. Updated systematic review and meta-analysis of the comparative data on colposuspension, pubovaginal slings and midurethal tapes in the surgical treatment of female stress urinary incontinence. Eur Urol 2010;58(2):21838.

[35] Abdel-fattah M, Ramsay I. Transobturator tension free vaginal tapes: Are they the way forward in the surgical treatment of urodynamic stress incontinence? Int J of Surgery 2007;5(1):3-10.

[36] Rajamaheshwari N, Varghese L. Transobturator tapes are preferable over transvaginal tapes for the management of female stress urinary incontinence: For. Indian J Urol 2009;25(4):550-3. 